\title{
Esterification of High Free Fatty Acid Rice Bran Oil: Parametric and Kinetic Study
}

\author{
R. Arora, ${ }^{\mathrm{a}, \mathrm{b}}$ A. P. Toor, ${ }^{\mathrm{a}, \mathrm{c}, \mathrm{w}}$ and R. K. Wanchoo ${ }^{\mathrm{a}}$ \\ ${ }^{a}$ Dr S S Bhatnagar University Institute of Chemical Engineering \\ \& Technology, Panjab University, Chandigarh, India \\ ${ }^{b}$ Shaheed Bhagat Singh State Technical Campus, Ferozepur, India \\ ${ }^{c}$ Energy Research Centre, Panjab University, Chandigarh, India
}

doi: 10.15255/CABEQ.2014.2117

Original scientific paper

Received: September 21, 2014

Accepted: December 8, 2015

\begin{abstract}
The esterification of free fatty acids (FFA) in rice bran oil (RBO) with methanol in the presence of sulfuric acid as a homogeneous catalyst was studied. The effects of catalyst concentration $(0.15$ to $1.0 \mathrm{wt} \%)$, reaction temperature $(318 \mathrm{~K}$ to $333 \mathrm{~K})$, and molar ratio of oil to methanol (1:5 to $1: 30)$ on the conversion of FFA were investigated to optimize the conditions for maximum conversion of FFAs. A detailed kinetic study was carried out using second-order pseudo-homogeneous kinetic model. The kinetic parameters were obtained and activation energy was determined from the Arrhenius plot. The activation energy of $23.21 \mathrm{~kJ} \mathrm{~mol}^{-1}$ and pre-exponential factor of $32.65 \mathrm{~L} \mathrm{~mol}^{-1} \mathrm{~min}^{-1}$ was obtained under the optimum catalyst concentration of $0.5 \mathrm{wt} \%$, stirring speed of $500 \mathrm{rpm}$ and oil to methanol ratio 1:20.
\end{abstract}

Key words:

biodiesel, esterification, high free fatty acid oil, homogeneous catalyst, kinetics

\section{Introduction}

Increased global industrialization has led to a steep rise in the demand for energy. The global demand for energy is expected to increase by about $1.6 \%$ per annum from 2011 to $2030^{1}$. Fossil fuels are expected to remain the main energy source in the world, but in the meantime renewable energy sources (wind, solar, geothermal, bioenergy) are the world's fastest-growing energy sources, increasing by 2.5 percent per year ${ }^{2}$. However, the reserves of fossil fuels are limited, and their large-scale use is associated with environmental deterioration ${ }^{3,4}$. The negative effects of using fossil fuels include acid rain, ozone layer depletion, and global climate change ${ }^{5}$. The increase in oil price and the growing interest in environmental issues have recently given a considerable impetus to the research for cleaner and renewable energy sources.

Biodiesel, which consists of long-chain Fatty Acid Methyl Esters (FAME) obtained from renewable lipids, such as those in vegetable oils or animal fat, can be used both as an alternative fuel and as an additive for petroleum diesel. As much as 70-80\% of the cost of biodiesel is associated with the cost of raw material. Using a low-cost raw material, such as crude oils, acid oils, waste oils or high FFA rice bran oil (RBO) to produce biodiesel is important in reducing the cost of biodiesel production ${ }^{6}$.

"Corresponding author: E-mail: aptoor@yahoo.com
Nevertheless, the biggest challenge in using FFA feedstock is that, during transesterification, these feedstocks easily undergo the saponification reaction leading to soap formation. Saponification results in reduced biodiesel yields, hinders separation of the ester from glycerin and reduces the formation rate of $\mathrm{FAME}^{7,8}$. Therefore, alkaline catalysts cannot directly catalyze the transesterification of oils containing high FFA. For alkaline transesterification to take place, the FFA level in the oil should be below a desired level (ranging from less than $0.5 \%$ to less than $3 \%)^{9}$. As a result, a two-step process is usually employed to prepare biodiesel from high FFA feedstocks. In the first step, the raw material undergoes acid pretreatment before being subjected to alkali-catalyzed transesterification. The acid-catalyzed chemical reaction, also referred to as esterification, involves the reaction of FFAs and alcohol, yielding fatty acid alkyl ester and water ${ }^{10}$. The reduction of free fatty acids in different oils and fats by esterification has been proposed in many studies $^{11-14}$. Acid catalysis is more tolerant to high FFA and moisture levels in the initial feedstock, and therefore, is more appropriate for low-quality oils ${ }^{15,16}$. A homogeneous acid, such as sulfuric acid $\left(\mathrm{H}_{2} \mathrm{SO}_{4}\right)$, shows a better performance with FFAs than the solid-base catalysts, while it can simultaneously catalyze esterification and transesterification $^{17,18}$.

Rice bran oil offers significant potential as an alternative low-cost feedstock for biodiesel produc- 
tion. Rice bran, the cuticle between the paddy husk and the rice grain and is obtained as a by-product of rice processing, is the main source of RBO. The annual world rice cultivation yields approximately 47 million tons of rice bran, from which about 9 million tons of RBO could be available for the production of biodiesel. Maximum production of rice is in Asian countries and the prospective biodiesel production from RBO in Asian countries is about 10 billion liters, which amounts to approximately $10 \%$ of Asia's diesel requirements. Rice bran contains $15-27 \%$ oil, while crude RBO from fresh rice bran contains 6-8 \% FFA. Due to the presence of active enzymes in rice bran, the FFA content in rice bran during storage increases by $1-7 \%$ per day. The crude RBO can be refined to edible oil only if the FFA content in the oil is less than $10 \%$. It is not possible to extract RBO immediately after the milling of rice, due to which most of the high FFA rice bran remains underutilized ${ }^{19}$.

Due to the huge availability of high FFA-RBO, the unavoidable need to remove FFA and the requirement of characterizing the kinetics of the reaction with a view to optimizing the reactor dimensions led us to undertake the present work. The influence of operational variables on the kinetics of the esterification of FFA in RBO using sulfuric acid as catalyst were studied. The reaction kinetics were developed based on pseudo-homogeneous, first-order in forward direction and second-order esterification of FFA.

\section{Materials and methods}

\section{Materials}

Raw high FFA-RBO was purchased from the solvent extraction unit located near Chandigarh (India), which was filtered with a 10 micron filter cloth. The acid value was determined to be $24 \mathrm{mg} \mathrm{KOH} \mathrm{g}^{-1}$ oil. The average molecular weight of RBO is calculated based on its FFA and TG content, assuming a molecular weight of 870 for TG and 282 for FFA 9 . The chemicals used in esterification were methyl alcohol (99.0 \% purity) and $\mathrm{H}_{2} \mathrm{SO}_{4}(98 \%$ purity), which were purchased from SD Fine Chemicals (India). The reagents used in the free fatty acids determination included potassium hydroxide $(\mathrm{KOH}, 99.9$ $\%$ purity), ethanol ( $99.9 \%$ purity), diethyl ether and phenolphthalein indicator, which were also purchased from SD Fine Chemicals (India). All the chemicals and reagents were of analytical grade.

\section{Esterification}

The esterification was carried out in a $500-\mathrm{mL}$ water-jacketed flat-bottom glass batch reactor working with total reflux. An amount of $100 \mathrm{gm}$ of RBO was preheated to the required temperature (varied from $318 \mathrm{~K}$ to $333 \mathrm{~K}$ ). Varying quantities of sulfuric acid as catalyst $(0.15$ to $1.0 \mathrm{wt} \%)$ were mixed in methanol (oil to methanol molar ratio varying from 1:5 to 1:30) and the resulting mixture was allowed to react with the preheated oil. The reaction was carried out for 2 hours using a temperature-controlled magnetic stirrer having one-inch magnetic bead. Samples were collected at different time intervals $(5,15,30,50,70,90$ and $120 \mathrm{~min})$, washed with distilled water to remove residual acid and impurities, dried to remove residual water and tested for acid value.

All experiments were carried out at atmospheric pressure. The standard error obtained in the calculation of the acid value was $\pm 1-2 \%$ for the duplicate set of reactions.

\section{FFA analysis}

The sample collected from the reaction was weighed and then dissolved in diethyl ether-ethanol solution. The mixture was titrated against standard $\mathrm{KOH}$ solution of known normality with phenolphthalein as an indicator. The acid value (AV) of the sample is defined as follows:

$$
A V=\frac{M_{w} \cdot c \cdot V}{m}
$$

where $M_{W}$ is the molecular weight of $\mathrm{KOH}, c$ is the molar concentration of $\mathrm{KOH}, V$ is the volume of $\mathrm{KOH}$ used in the titration process, and $m$ is the sample weight. Once the acid value is determined, the FFA conversion can be calculated as follows:

$$
X=\left(1-\frac{A V}{A V_{0}}\right)
$$

where $X$ is the FFA conversion and $A V_{0}$ is the initial acid value before the esterification reaction.

\section{Results and discussion} is

The esterification using $\mathrm{H}_{2} \mathrm{SO}_{4}$ as acid catalyst

$$
\mathrm{R}_{1}-\mathrm{COOH}+\mathrm{CH}_{3}-\mathrm{OH} \stackrel{\mathrm{H}_{2} \mathrm{SO}_{4}}{\rightleftharpoons} \mathrm{R}_{1}-\mathrm{COO}-\mathrm{CH}_{3}+\mathrm{H}_{2} \mathrm{O}
$$

In this work, $R_{1}$ was a linear chain of 11-17 carbon atoms containing a variable number of unsaturations depending on the particular origin of the raw material, and $R_{2}$ was a methyl radical. A parametric study was carried out to establish the optimum parameters for this reaction. The parameters included catalyst concentration, oil to methanol ratio, reaction temperature and time of reaction. The 
Table 1 -Variation of parameters for the esterification of FFA in $R B O$

\begin{tabular}{lc}
\hline \multicolumn{1}{c|}{ Parameter } & Studied values \\
\hline Catalyst concentration (wt\%) & $0.15,0.25,0.5,1.0$ \\
Oil to methanol molar ratio & $1: 5,1: 10,1: 20,1: 30$ \\
Temperature (K) & $318,323,328,333$ \\
Reaction time (min) & $15,30,50,70,90,120$ \\
\hline
\end{tabular}

parameters and the operating conditions of the experimental runs are summarized in Table 1. The presence or absence of mass transfer effect was established by carrying out experiments at different revolutions per minute (rpm).

\section{Effect of external mass transfer}

Methanol is meagerly soluble in rice bran oil; thus, it requires agitation in order to avoid mass transfer taking control over the process. Tests were conducted at variable agitation speeds from 200 to $600 \mathrm{rpm}$ (at $0.5 \mathrm{wt} \% \mathrm{H}_{2} \mathrm{SO}_{4}, 1: 20$ oil to methanol ratio and $333 \mathrm{~K}$ ). As shown in Figure 1, there was an increase in conversion when the stirrer speed was increased from $200 \mathrm{rpm}$ to $500 \mathrm{rpm}$. However, above $500 \mathrm{rpm}$, it was observed that there had been no further increase in FFA conversion. This indicates the absence of external mass transfer limitations above $500 \mathrm{rpm}$. Therefore, a speed of $500 \mathrm{rpm}$ was subsequently used to examine the influence of other parameters.

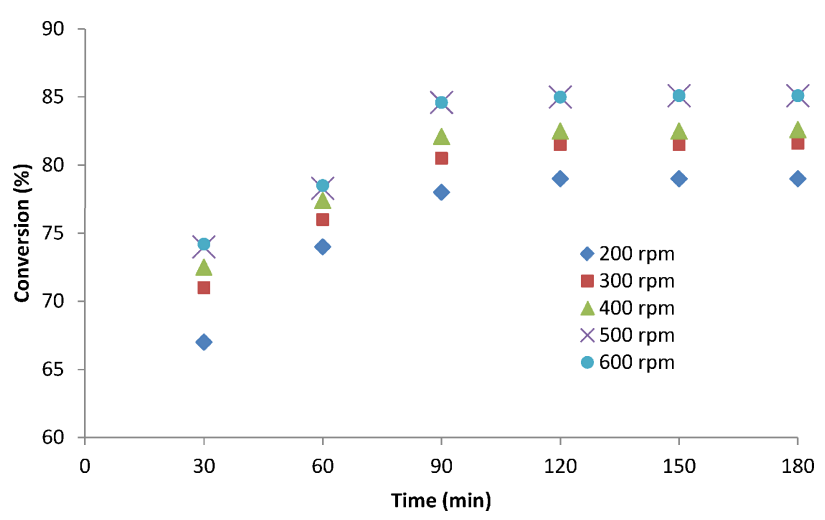

Fig. 1 - FFA conversion at different agitator speed with 1:20 oil to methanol ratio, catalyst (sulfuric acid) concentration $0.5 \mathrm{wt} \%$ and at temperature $333 \mathrm{~K}$

\section{Effect of oil to methanol molar ratio}

Oil to methanol molar ratio is an important parameter that affects the yield of the biodiesel. The esterification reaction between the FFA and methanol follows reversible kinetics. To obtain a higher equilibrium conversion, the backward reaction can be minimized with the use of excess methanol ${ }^{20}$.

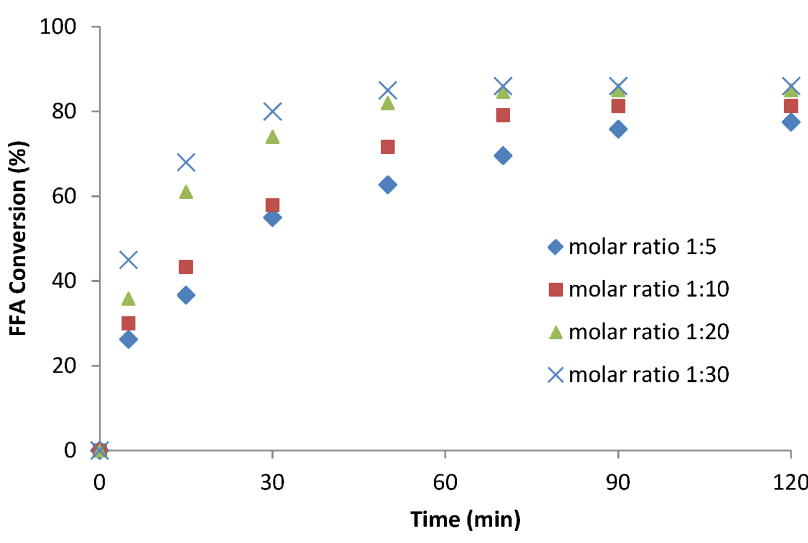

Fig. 2 - FFA conversion with change in oil to methanol molar ratio at catalyst (sulfuric acid) concentration $0.5 \mathrm{wt} \%$ and at $500 \mathrm{rpm}$ at $333 \mathrm{~K}$

Figure 2 presents the FFA conversion with time at various molar ratios. There was an increase in conversion as oil to methanol ratio increased from 1:5 to $1: 30$. This shows that the esterification rate increases with the molar ratio. Similar trends were obtained in other research on esterification of nonanoic acid and lactic acid ${ }^{21,22}$. There was no significant increase in conversion when the molar ratio increased beyond 1:20. Although using excess methanol speeds up the reaction, it also increases the operating cost and reactor size ${ }^{23}$. Hence, 1:20 was taken as the optimum molar concentration for further study.

\section{Effect of catalyst concentration}

The amount of acid catalyst used in the process also affects the FFA conversion. Experiments were carried out by changing the catalyst $\left(\mathrm{H}_{2} \mathrm{SO}_{4}\right)$ amount in the range of $0.15-1.0(\mathrm{wt} \%)$ at a temperature of $333 \mathrm{~K}, 1: 20$ oil to methanol molar ratio and at stirrer speed of $500 \mathrm{rpm}$. The increase in FFA conversion is shown in Figure 3. Conversion increases with increased catalyst quantity up to $0.5 \%$ of the catalyst. Below $0.5 \%$ concentration, the final acid value of oil remains above 4 , which is higher and

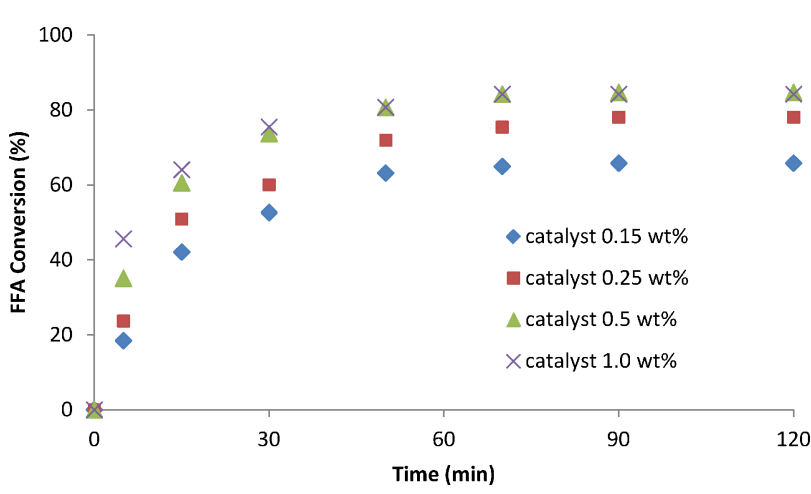

Fig. 3 - FFA conversion with catalyst (sulfuric acid) conc. at oil/methanol ratio 1:20 at $500 \mathrm{rpm}$ and $333 \mathrm{~K}$ 
transesterification cannot be done. From Figure 3, it is evident that the conversion of FFA becomes almost constant as the catalyst concentration is increased beyond $0.5 \%$. The optimum catalyst concentration was taken as $0.5 \%$.

\section{Effect of temperature of reaction}

Once the oil to methanol ratio of 1:20 and catalyst concentration of $0.5 \mathrm{wt} \%$ were adopted as optimal, the influence of temperature was examined. As shown in Figure 4, reaction temperature evidently influences esterification. The maximum FFA conversion was obtained at $333 \mathrm{~K}$. A higher temperature obviously increased the rate further, but required using a pressure above atmospheric level. The reaction temperature above boiling point of methanol $(338 \mathrm{~K})$ cannot be used since at higher temperature, it tends to lose methano ${ }^{24}$.

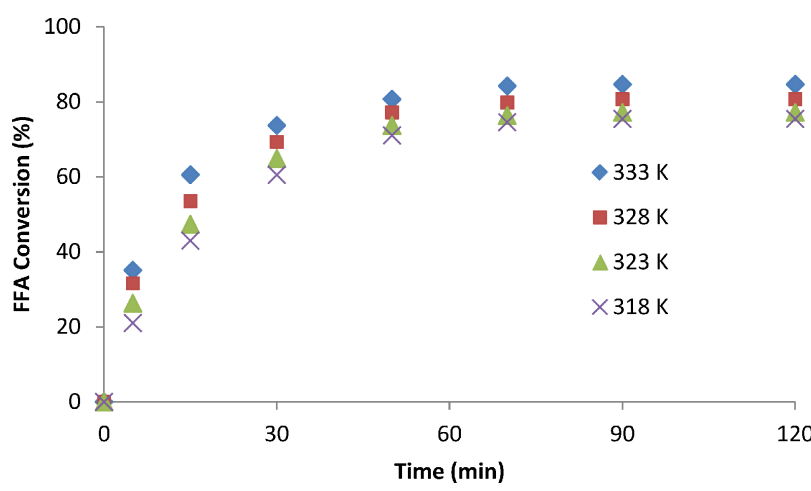

Fig. 4 - FFA conversion with temperature at 1:20 oil/methanol mole ratio, at $500 \mathrm{rpm}$ and catalyst (sulfuric acid) concentration $0.5 \mathrm{wt} \%$

\section{Kinetic model}

The esterification reaction was a reversible reaction, the rate of which under the operating conditions used was controlled by the chemical reaction, as there is no external mass transfer above $500 \mathrm{rpm}$. The chemical reaction occurred in the oil phase.

With the above consideration, the rate of reaction for this esterification reaction

$$
\mathrm{RBO}(\mathrm{A})+\operatorname{Methanol}(\mathrm{B}) \rightleftharpoons \operatorname{Ester}(\mathrm{C})+\text { Water }(\mathrm{D})
$$

is

$$
-\frac{\mathrm{d} C_{A}}{\mathrm{~d} t}=k_{1} C_{B} C_{A}-k_{2} C_{C} C_{D}
$$

where $C_{A}$ denotes the concentration of FFA in RBO, $C_{B}, C_{C}$ and $C_{D}$ are the concentrations of methanol, ester and water respectively; and $k_{1}$ and $k_{2}$ are the kinetic constants for the forward and reverse reaction, respectively.
Since the methanol to oil ratio was very high, it was assumed that $C_{B}$ is almost constant. Eq. (5) can be written as:

$$
\begin{gathered}
-\frac{\mathrm{d} C_{A}}{\mathrm{~d} t}=C_{A_{0}} \frac{\mathrm{d} X_{A}}{\mathrm{~d} t}= \\
=k_{1}\left[C_{B_{0}}\left(C_{A_{0}}-C_{A_{0}} x_{A}\right)-\frac{C_{A_{0}} x_{A} C_{A_{0}} x_{A}}{K_{e}}\right]
\end{gathered}
$$

where equilibrium conversion, $K_{e}=k_{1} / k_{2}$.

Thus, this reaction is pseudo-homogeneous, first-order in forward direction and second-order in reverse direction. A general expression for this esterification reaction is

$$
\begin{gathered}
\frac{2 \sqrt{K_{e}} \tanh ^{-1}\left[\frac{2 C_{A_{0}} x_{A}+C_{B_{0}} K_{e}}{\sqrt{C_{B_{0}} K_{e}\left(4 C_{A_{0}}+C_{B_{0}} K_{e}\right)}}\right]}{\sqrt{C_{B_{0}}\left(4 C_{A_{0}}+C_{B_{0}} K_{e}\right)}}- \\
-\frac{2 \sqrt{K_{e}} \tanh ^{-1}\left[\frac{C_{B_{0}} K_{e}}{\sqrt{C_{B_{0}} K_{e}\left(4 C_{A_{0}}+C_{B_{0}} K_{e}\right)}}\right]}{\sqrt{C_{B_{0}}\left(4 C_{A_{0}}+C_{B_{0}} K_{e}\right)}}=k_{1} t
\end{gathered}
$$

This can be simplified to

$$
Y=k_{1} t
$$

where

$$
\begin{gathered}
Y=\frac{2 \sqrt{K_{e}} \tanh ^{-1}\left[\frac{2 C_{A_{0}} x_{A}+C_{B_{0}} K_{e}}{\sqrt{C_{B_{0}} K_{e}\left(4 C_{A_{0}}+C_{B_{0}} K_{e}\right)}}\right]}{\sqrt{C_{B_{0}}\left(4 C_{A_{0}}+C_{B_{0}} K_{e}\right)}} \\
-\frac{2 \sqrt{K_{e}} \tanh ^{-1}\left[\frac{C_{B_{0}} K_{e}}{\sqrt{C_{B_{0}} K_{e}\left(4 C_{A_{0}}+C_{B_{0}} K_{e}\right)}}\right]}{\sqrt{C_{B_{0}}\left(4 C_{A_{0}}+C_{B_{0}} K_{e}\right)}}
\end{gathered}
$$

The rate constant for the forward reaction $\left(k_{1}\right)$ was obtained by plotting $Y$ of Eq. (8) vs. time (t). Table 2 contains the calculated rate constants for different reaction temperatures. The value of rate constants obtained are close to the values reported by other researchers ${ }^{25,26}$.

The influence of temperature on specific reaction rate was determined by fitting $k_{1}$ to the Arrhenius equation,

$$
k=k_{o} \cdot e^{-\frac{E}{R \cdot T}}
$$

using plot of $-\ln k_{1}$ as a function of reciprocal temperature, $T$ (Figure 5). $k_{o}$ is pre-exponential factor, $E$ is activation energy and $R$ is ideal gas constant $\left[\mathrm{J} \mathrm{mol}^{-1} \mathrm{~K}^{-1}\right]$. 


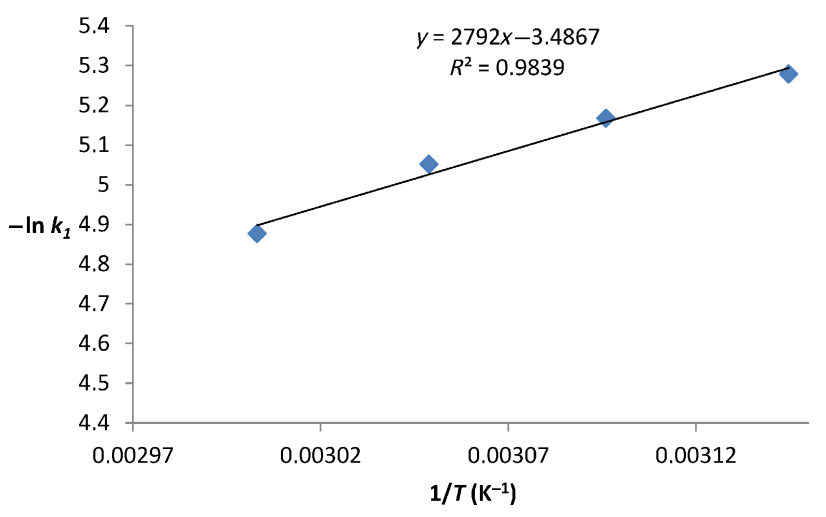

Fig. 5 - Influence of temperature on specific reaction rate (Arrhenius equation) at a sulfuric acid concentration of $0.5 \mathrm{wt} \%$, at $500 \mathrm{rpm}$ and oil to methanol ratio $1: 20$

Table 2 - Reaction rate constants at $0.5 w t \%$ catalyst and oil to methanol ratio of $1: 20$

\begin{tabular}{ccc}
\hline Temperature $(\mathrm{K})$ & $k_{1}\left(\mathrm{~L} \mathrm{~mol}^{-1} \mathrm{~min}^{-1}\right)$ & $K_{e}$ \\
\hline 318 & 0.00510 & 0.115852 \\
323 & 0.00570 & 0.130634 \\
328 & 0.00640 & 0.168740 \\
333 & 0.00762 & 0.233390 \\
\hline
\end{tabular}

A satisfactory linear coefficient of 0.983 was obtained. The slope of the straight line in Figure 5 can be applied to calculate the activation energy. The activation energy for the forward reaction was $23.21 \mathrm{~kJ} \mathrm{~mol}^{-1}$ and pre-exponential factor $32.65 \mathrm{~L} \mathrm{~mol}^{-1} \mathrm{~min}^{-1}$. This value is comparable to the activation energy in the range of 20.7 to $45.9 \mathrm{~kJ} \mathrm{~mol}^{-1}$ when calculated by first-order reaction kinetics ${ }^{27-29}$. For heterogeneous catalysts, the activation energy for esterification of different oils is generally high$\mathrm{er}^{23,25,26,30}$. By applying the Arrhenius equation to the values of slope and intercept of graphs, the temperature dependency of the constants can be correlated by the following equations:

and

$$
k_{1}=\exp \left[3.486-\frac{2792}{T}\right]
$$

$$
K_{e}=\exp \left[13.72-\frac{5071}{T}\right]
$$

\section{Reaction enthalpy, entropy and free energy}

Assuming constant reaction enthalpy within the operating temperature range, the reaction enthalpy $\Delta H_{r}$ and entropy $\Delta S_{r}$ can be estimated by setting the experimental values of eqs. 10 and 11 into the following equation:

$$
\ln K_{e}=\left[\frac{-\Delta H_{r}}{R T}+\frac{\Delta S_{r}}{R}\right]
$$

The reaction enthalpy $\Delta H_{r}$ and entropy $\Delta S_{r}$ are found to be $42.16 \mathrm{~kJ} \mathrm{~mol}^{-1}$ and $0.114 \mathrm{~kJ} \mathrm{~mol}^{-1} \mathrm{~K}^{-1}$. Furthermore, the liquid phase reaction free energy change at $333 \mathrm{~K}$ can be calculated to be $\Delta G_{r}=\Delta H_{r}-T \Delta S_{r}$ $=4.198 \mathrm{~kJ} \mathrm{~mol}^{-1}$ and the value of $\Delta G_{r}$ explains the reason for non-spontaneity and it is in good agreement with the reported literature ${ }^{31,32}$.

\section{Model prediction}

For all calculated values of $k_{1}$, good linear correlation in the range of 0.97 to 0.999 was obtained. Hence, the proposed kinetic model is appropriate for this reaction. Similar trends were obtained in the esterification of acetic acid also ${ }^{33}$. The goodness-offit of the experimental data to this kinetic model was assessed by comparing the experimental FFA conversion with the theoretical prediction of Eq. (8). As can be observed in Figure 6, the errors between the experimental and the predicted data were within $\pm 10 \%$, which demonstrated the validity of the kinetic model adopted.

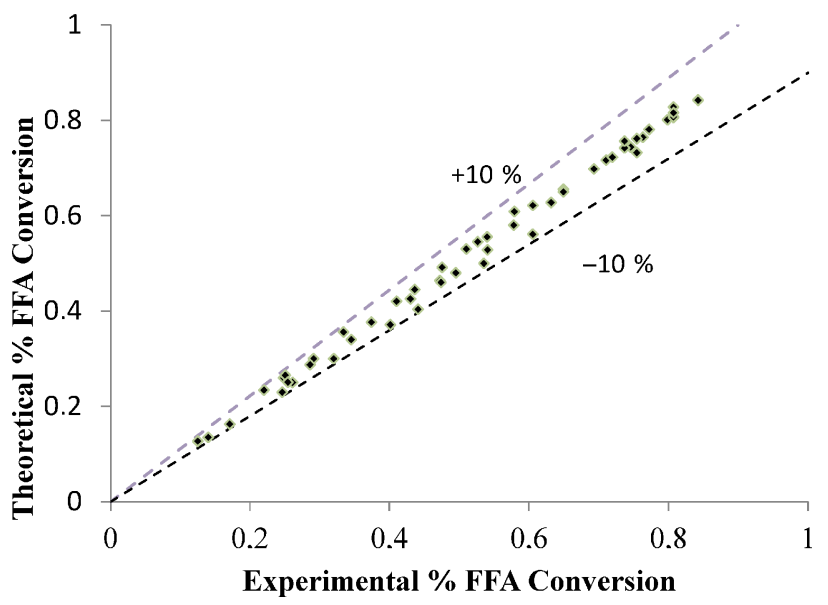

Fig. 6 - Comparison of experimental and theoretical \% FFA conversion

\section{Conclusion}

The effects of catalyst concentration, temperature, agitation and methanol to oil molar ratio on FFA esterification in $12 \%$ FFA rice bran oil with methanol, using sulfuric acid as homogeneous catalyst, were studied. Maximum FFA conversion of $85 \%$ was obtained with the optimum catalyst concentration $0.5 \mathrm{wt} \%$, oil to methanol molar ratio 1:20, agitation speed $500 \mathrm{rpm}$ and at a temperature $333 \mathrm{~K}$ in 90 minutes. A pseudo-homogeneous second-order reversible model was demonstrated to justify the experimental data and the activation energy was $23.21 \mathrm{~kJ} \mathrm{~mol}^{-1}$. This model was provided a satisfactory interpretation of the experimental results. 


\section{ACKNOWLEDGMENT}

We gratefully acknowledge the experimental support from Energy Research Centre, Panjab University, Chandigarh (India).

\section{Notations}

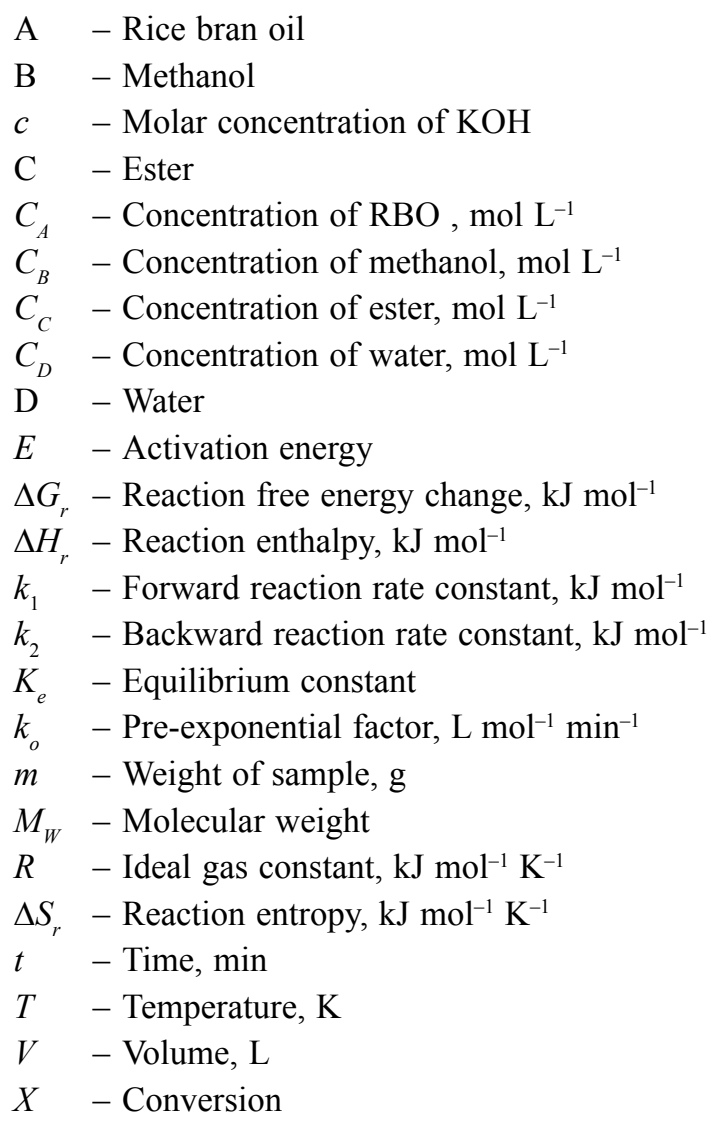

\section{Abbreviations}

$\begin{array}{ll}\text { AV } & - \text { Acid Value } \\ \text { FAME } & \text { - Fatty Acid Methyl Ester } \\ \text { FFA } & - \text { Free Fatty Acid } \\ \text { RBO } & - \text { Rice Bran Oil } \\ \text { TG } & - \text { Triacylglycerol }\end{array}$

\section{References}

1. Dudley, B., BP's Energy Outlook 2030, BP p.1.c London, United Kingdom, 2013, pp. 9.

2. Holtberg, P., International Energy Outlook, U.S. Energy Information Administration, Washington DC, 2013, pp. 9.

3. Manzano-Agugliaro, F., Hernandez-Escobedo, Q., Zapata-Sierra, A., Use of bovine manure for ex situ bioremediation of diesel contaminated soils in Mexico, Itea-inform. Tecn. Econ. 106(3) (2010) 197.

4. Manzano-Agugliaro, F., Sanchez-Muros, M. J., Barroso, F. G., Martínez-Sánchez, A., Rojo, S., Pérez-Bañón, C., Insects for biodiesel production, Renew. Sust. Energy Rev. 16(6) (2012) 3744.
5. Kalogirou, S. A., Solar thermal collectors and applications, Prog. in Energy and Comb. Sci. 30(3) (2004) 231

6. Zullaikah, S., Lai, C. C., Vali, S. R., Ju, Y. H., A two-step acid-catalyzed process for the production of biodiesel from rice bran oil, Biores. Tech. 96 (2005) 1889. doi: http://dx.doi.org/10.1016/j.biortech.2005.01.028

7. Thiruvengadaravi, K. V., Nandagopal, J., Baskaralingam, P., Sathya Selva Bala, V., Sivanesan, S., Acid-catalyzed esterification of karanja (Pongamia pinnata) oil with highfree fatty acids for biodiesel production, Fuel 98 (2012) 1. doi: http://dx.doi.org/10.1016/j.fuel.2012.02.047

8. Saraf, S., Thomas, B., Influence of Feedstock and Process Chemistry on Biodiesel Quality, IChemE 85(B5) (2007) 360. doi: http://dx.doi.org/10.1205/psep07025

9. Sharma, Y. C., Singh, B., Development of biodiesel: Current scenario, Renew. Sust. Energy Rev. 13 (2009) 1646. doi: http://dx.doi.org/10.1016/j.rser.2008.08.009

10. Atadashi, I. M., Aroua, M. K., Abdul Aziz, A. R., Sulaiman, N. M. N., Production of biodiesel using high free fatty acid feedstocks, Renew. Sust. Energy Rev. 16 (2012) 3275. doi: http://dx.doi.org/10.1016/j.rser.2012.02.063

11. Canackci, M., Gerpen, J. V., Biodiesel production from oils and fats with high free fatty acids, Trans. ASAE 44 (2001) 1429.

12. Hayyan, A., Alam, M. Z., Kabbashi, N. A., Mirghani, M. E. S., Hakimi, N. I. N. M., Siran, Y. M., Pretreatment of sludge palm oil for biodiesel production by esterification, Proc. Symposium of Malaysian Chemical Engineers, Kuala Lumpur, Malaysia 2 (2008) 485.

13. Naik, M., Meher, L. C., Naik, S. N., Das, L. M., Production of biodiesel from high free fatty acid Karanja (pongamia pinnata) oil, Biomass Bioenerg. 32 (2008) 354. doi: http://dx.doi.org/10.1016/j.biombioe.2007.10.006

14. Hayyan, A., Alam, M. Z., Kabbashi, N. A., Mirghani, M. E. S., Hakimi, N. I. N. M., Siran, Y. M., Reduction of high content of free fatty acid in sludge palm oil via acid catalyst for biodiesel production, Fuel Proc. Tech. 92 (2011) 920. doi: http://dx.doi.org/10.1016/j.fuproc.2010.12.011

15. Cardoso, A. L., Nevesm, S. C. G., da Silva, M. J., Esterification of oleic acid for biodiesel production catalyzed by $\mathrm{SnCl}_{2}$ : a kinetic investigation, Energies 1 (2008) 79. doi: http://dx.doi.org/10.3390/en1020079

16. Singh, S. P., Singh, D., Biodiesel production through the use of different sources and characterization of oils and their esters as the substitute of diesel: a review, Renew. Sust. Ener. Rev. 14 (2010) 200. doi: http://dx.doi.org/10.1016/j.rser.2009.07.017

17. Lotero, E., Liu, Y. J., Lopez, D. E., Suwannakarn, K., Bruce, D. A., Goodwin, J. G., Synthesis of biodiesel via acid catalysis. Ind. Eng. Chem. Res. 44 (2005) 5353. doi: http://dx.doi.org/10.1021/ie049157g

18. Goff, M. J., Bauer, N. S., Lopes, S., Sutterlin, W. R., Suppes, $G . J$. , Acid-catalyzed alcoholysis of soybean oil, J. Am. Oil Chem. Soc. 81 (2004) 415. doi: http://dx.doi.org/10.1007/s11746-004-0915-6

19. Pandey, A., Handbook of Plant-Based Biofuels, CRC Press, New York, 2009, pp, 243-44.

20. Deshmane, V. G., Gogate, P. R., Pandit, A. B., Ultrasound Assisted Synthesis of Biodiesel from Palm Fatty Acid Distillate, Ind. Eng. Chem. Res. 48 (2009) 7923. doi: http://dx.doi.org/10.1021/ie800981v

21. Sharma, M., Wanchoo, R. K., Toor, A. P., Adsorption and kinetic parameters for synthesis of methyl nonanoate over heterogeneous catalysts, Ind. Engg. Chem. Res. 51 (2012) 14367. doi: http://dx.doi.org/10.1021/ie301661n 
22. Toor, A. P., Sharma, M., Thakur, S., Wanchoo, R. K., Ion-exchange resin catalyzed esterification of lactic acid with isopropanol: a kinetic study, Bull. of Chem. Reac. Eng. \& Cata. 6 (2011) 39.

doi: http://dx.doi.org/10.9767/bcrec.6.1.791.39-45

23. Berrios, M., Siles, J., Martin, M. A., Martin, A., A kinetic study of the esterification of free fatty acids (FFA) in sunflower oil, Fuel 86 (2007) 2383.

doi: http://dx.doi.org/10.1016/j.fuel.2007.02.002

24. Lin, L., Ying, D., Chaitep, S., Vittayapadung, S., Biodiesel production from crude rice bran oil and properties as fuel, Appl. Ener. 86 (2009) 681 doi: http://dx.doi.org/10.1016/j.apenergy.2008.06.002

25. Patel, A., Singh, S., Kinetic study of oleic acid esterification over 12-tungstophosphoric acid catalyst anchored to different mesoporous silica supports, Fuel Proc. Tech. 113 (2013) 141

doi: http://dx.doi.org/10.1016/j.fuproc.2013.03.022

26. $S u, C$., Kinetic study of free fatty acid esterification reaction catalyzed by recoverable and reusable hydrochloric acid, Biores. Tech. 130 (2013) 522.

doi: http://dx.doi.org/10.1016/j.biortech.2012.12.090

27. Chai, M., Tu, Q., Lu, M., Yang J. Y., Esterification pretreatment of free fatty acid in biodiesel production, from laboratory to industry, Fuel Proc. Tech. 125 (2014) 106. doi: http://dx.doi.org/10.1016/j.fuproc.2014.03.025
28. Sendzikiene, E., Makareviciene, V., Janulis, P., Kitrys, S., Kinetics of free fatty acids esterification with methanol in the production of biodiesel fuel, Eur. J. of Lipid Sc. and Tech. 106 (2004) 831. doi: http://dx.doi.org/10.1002/ejlt.200401011

29. Satriana, M. D., Supardan, Kinetic study of esterification of free fatty acid in low-grade crude palm oil using sulfuric acid, ASEAN Journal of Chemical Engineering 8 (2008) 1.

30. Mengyu, G., Deng, P., Li, M., En, Y., Jianbing, H., The Kinetics of the Esterification of Free Fatty Acids in Waste Cooking Oil Using $\mathrm{Fe}_{2}\left(\mathrm{SO}_{4}\right)_{3} / \mathrm{C}$ Catalyst, Chin. J. of Chem. Eng. 17(1) (2009) 83. doi: http://dx.doi.org/10.1016/S1004-9541(09)60037-9

31. Patel, A., Singh, S., A green and sustainable approach for esterification of glycerol using 12-tungstophosphoric acid anchored to different supports: Kinetics and effect of support, Fuel 118 (2014) 358. doi: http://dx.doi.org/10.1016/j.fuel.2013.11.005

32. Liao, X., Zhu, Y., Wang, S. G., Chen, H., Li, Y., Chemical Kinetics for Synthesis of Triacetin from Biodiesel Byproduct, Appl. Cata. B: Environ. 94 (2010) 64. doi: http://dx.doi.org/10.1016/j.apcatb.2009.10.021

33. Toor, A. P., Sharma, M., Kumar, G., Wanchoo, R. K., Kinetic study of esterification of acetic acid with n-butanol and isobutanol catalyzed by ion exchange resin, Bull. of Chem. Reac. Eng. \& Cata. 6(1) (2011) 23. doi: http://dx.doi.org/10.9767/bcrec.6.1.665.23-30 